http://jmscr.igmpublication.org/home/

ISSN (e)-2347-176x ISSN (p) 2455-0450

crossref DOI: https://dx.doi.org/10.18535/jmscr/v8i1.82

\title{
A hospital based study to evaluate the prevalence of Diabetic nephropathy by considering Microalbuminuria as early risk marker in type 2 diabetic subjects
}

\author{
Author
}

Dr S. R. Pattanaik

Associate Professor, Department of Endocrinology, MKCG Medical College, Berhampur, Odisha

\begin{abstract}
Aim: For progression of nephropathy increase in Microalbuminuria is consider as a one of the major risk factor for Type 2 Diabetes (T2DM). The main aim of the study is to evaluate the correlation between other risk factor and Microalbuminuria in the development of Diabetic Neuropathy (DN) among T2DM subjects.

Methods: For this study 382 subjects were recruited from a hospital OPD in for this study. Medical record were used to collect demographic history like age, duration of T2DM, history of hypertension and Body Mass Index (BMI). Blood specimen was collected to perform pathological test like Glycosylated haemoglobin (HbAlC), fasting blood glucose (FBG), serum uric acid and serum creatinine. By using the dipstick method in early morning urine samples, Microalbuminuria was quantified.

Results: 137 subjects were having high Microalbuminuria. It has been also observed that the subjects who were having higher Microalbuminuria having higher glycemic parameters (both HbAlc and FPG) $(p<0.001)$ and blood pressure (both systolic and Diastolic) $(p<0.001)$ as compare to subjects who had normal Microalbuminuria or normoalbuminuria subjects. It has been also assed that there were also a significant association between other risk factors like duration of T2DM, Age, BMI, serum creatinine with increase in Microalbuminuria.

Conclusion: There were overall very high prevalence of Microalbuminuria was present in this observational study among T2DM subjects who were at high risk of DN. Looking at the future to reduce the high burden of kidney disease among T2DM early detection of higher level Microalbuminuria was of high importance.

Keywords: Microalbuminuria, Glycosylated hemoglobin (HbAlc), Fasting Plasma Glucose (FPG), Blood Pressure (BP), Risk Factors.
\end{abstract}

\section{Introduction}

Type 2 Diabetes (T2DM) itself is one the major and leading cause of morbidity and mortality not only in India but around the world ${ }^{[1]}$. One of the leading cause of morbidity and mortality among T2DM is diabetic complications ${ }^{[2]}$. There were two major type of complication associated with T2DM which can be categorised as micro and macro vascular complication ${ }^{[3]}$. Long duration of diabetes with associated risk factors is cause of further consequence of diabetic neuropathy, diabetic nephropathy and diabetic retinopathy ${ }^{[4]}$. Out of these complications prevalence of diabetic nephropathy is on higher side in India especially in 
an underserved rural community ${ }^{[5]}$. Diabetic nephropathy was the commonest (44\%) cause of End Stage Renal Disease (ESRD $)^{[6]}$. Micro albuminuria is one of the major cause of early onset of diabetic nephropathy ${ }^{[7,8,9,10]}$. First sign of renal involvement which is predicting overt nephropathy in reduction in Microalbuminuria ${ }^{[11]}$. Thus along with other risk factors monitoring of Microalbuminuria is one the prime importance of prevent or postpone overt nephropathy. Awareness of regular urinary albumin screening is in utmost requirement in order to improve medical care of diabetic patient's among primary care clinicians across country including major city of eastern India.

The main aim of the study is to evaluate the correlation between other risk factor and Microalbuminuria in the development of Diabetic Neuropathy (DN) among T2DM subjects.

\section{Method}

For this study 382 subjects were recruited from a hospital OPD in teaching hospital for this study. According to American Diabetes Association (ADA) criteria T2DM was detected ${ }^{[12]}$. Medical record were used to collect demographic history like age, duration of T2DM, history of hypertension and Body Mass Index (BMI).
Patients who had fully or partial incomplete medical record, having proteinuria $>300 \mathrm{mg} /$ day, any infection including UTI and women with pregnancy were excluded from the study at initial level. Blood specimen was collected to perform pathological test like Glycosylated haemoglobin (HbA1C), fasting blood glucose (FBG), serum uric acid and serum creatinine. By using the dipstick method in early morning urine samples, Microalbuminuria was quantified. The statistical analysis was done by using SPSS, version 16.0. One Way ANOVA method was applied to observe the association between Microalbuminuria and Glycosylated Hemoglobin; duration of diabetes. The $p$ value of $\leq 0.0001$ was considered as statistically significant.

\section{Result}

137 subjects were having high Microalbuminuria among 382 subjects. It has been also observed that the subjects who were having higher Microalbuminuria having higher glycemic parameters (both HbA1c and FPG) $(\mathrm{p}<0.001)$ and blood pressure (both systolic and Diastolic) $(\mathrm{p}<0.001)$ as compare to subjects who had normal Microalbuminuria or normoalbuminuria subjects. Table 1 revels the outcome of the present study.

Table 1: Clinical and biochemical characteristics of study subjects

\begin{tabular}{|c|c|c|c|}
\hline Characteristics & $\begin{array}{c}\text { Normoalbuminuria } \\
\text { group }(n=245) \\
{[\text { Mean } \pm \text { SD] }}\end{array}$ & $\begin{array}{c}\text { Microalbuminuria } \\
\text { group }(n=137)[\text { Mean } \\
\pm \mathrm{SD}]\end{array}$ & P Value \\
\hline Age (years) & \pm 10.7 & \pm 10.3 & $<0.001$ \\
\hline BMI (kg/M2) & \pm 1.3 & \pm 1.2 & 0.821 \\
\hline $\begin{array}{l}\text { Duration of Diabetes } \\
\text { (Years) }\end{array}$ & $5.3 \pm 2.1$ & $6.8 \pm 2.3$ & $<0.001$ \\
\hline $\begin{array}{l}\text { Systolic Blood } \\
\text { pressure }(\mathrm{mmHg})\end{array}$ & $139 \pm 6$ & $148 \pm 4$ & $<0.001$ \\
\hline $\begin{array}{l}\text { Diastolic Blood } \\
\text { pressure }(\mathrm{mmHg})\end{array}$ & $88 \pm 3$ & $87 \pm 4$ & $<0.001$ \\
\hline FBG (mg/dl) & $186.2 \pm 21.4$ & $218.01 \pm 29.5$ & $<0.001$ \\
\hline $\operatorname{HbA1C}(\%)$ & $8.9 \pm 0.5$ & $9.9 \pm 1$ & $<0.001$ \\
\hline Creatinine $(\mathrm{mg} / \mathrm{dl})$ & \pm 0.3 & \pm 0.2 & $<0.001$ \\
\hline Uric acid (mg/dl) & \pm 1.3 & \pm 1.4 & $<0.001$ \\
\hline
\end{tabular}

Average mean age was 57.1 \pm 10.7 and 59.2 $\pm 10.3 \quad$ BMI was $25.2 \pm 1.3$ and $26.4 \pm 1.2$ respectively. It in respective group of subjects having was observed that age $(\mathrm{p}<0.001)$, Systolic Blood Normoalbuminuria and Microalbuminuria whereas pressure $(\mathrm{p}<0.001)$, Diastolic Blood pressure 
$(\mathrm{p}<0.001), \quad$ FBG $(\mathrm{p}<0.001), \quad$ HbA1c $\quad(\mathrm{p}<0.001)$, Creatinine $(\mathrm{p}<0.001)$ and Uric acid $(\mathrm{p}<0.001)$ was in higher side among Normoalbuminuria group as compare to Microalbuminuria group. BMI $(\mathrm{p}=0.821)$ were slightly statistically no significant among two groups.

\section{Discussion}

Prevalence of Microalbuminuria and its associated risk factors were studied here among 382 subjects who attended at a teaching hospital with tertiary medical care centre. The evidence of nephropathy was observed in 137 subjects (35.9\%). In a North Indian non proteinuric patients Gupta et al. ${ }^{[13]}$ reported a prevalence of $26.2 \%$ in $65 \mathrm{~T} 2 \mathrm{DM}$ subjects. Where as in South India $19.7 \%$ prevalence in Vellore ${ }^{[14]}$ and $15 \%$ in Chennai city ${ }^{[15]}$ was reported in two different trials.

In this study were found that microalbuminuria is a helpful predictor of renal failure in diabetic's condition as a usual risk poor glycaemic control and raised blood pressure. Duration of diabetes and additional risk factors for increasing microalbuminuria level, similar result was showed with previous study ${ }^{[16]}$.

Microalbuminuria has been considering as the earliest marker for should start with early diagnosis of kidney damage. The current study was showed a positive correlation of microalbuminuria with duration of diabetes and level of glycemic control (measured by HbA1c levels).

Present study, we were investigated on the bases of our result, evaluation of microalbuminuria in diabetes patients to emphasize the need for routine screening of glycemic control of risk factors.

\section{Conclusion}

There were overall very high prevalence of Microalbuminuria was present in this observational study among T2DM subjects who were at high risk of DN. Looking at the future to reduce the high burden of kidney disease among T2DM early detection of higher level Microalbuminuria was of high importance.

\section{Reference}

1. Suryawanshi KS, Jagtap PE, Belwalkar GJ, Dhonde SP, Nagane NS, Joshi VS.To study serum uric acid and urine microalbumin in type-2 diabetes mellitus. SSRG Int J Med Sci 2015; 2(3):24-9.

2. Wells BJ, Roth R, Nowacki AS, Arrigain S, Yu C, Rosenkrans WA, Jr, Kattan MW. Prediction of morbidity and mortality in patients with type 2 diabetes. Peer J. 2013; $1:$ e87.

3. Deng F, Wang S, Zhang L. Endothelial microparticles act as novel diagnostic and therapeutic biomarkers of diabetes and its complications: a literature review. Biomed Res Int. 2016;2016:9802026.

4. Papatheodorou K, Papanas N, Banach M, Papazoglou D, Edmonds M. Complications of Diabetes 2016. J Diabetes Res. 2016;2016:6989453.

5. Jindal R M, Salifu M O, Patel T G, Misra R. Prevalence of diabetic nephropathy in an underserved rural community. Indian J Nephrol 2012;22:484-5.

6. Modi GK, Jha V. The incidence of end-stage renal disease in India: A population-based study. Kidney Int 2006;70:2131-3.

7. Al-Saffar HB, Nassir H, Mitchell A, Philipp S. Microalbuminuria in non-diabetic patients with unstable angina/non ST-segment elevation myocardial infarction. BMC Res Notes. 2015;8:371. Published 2015 Aug 25. doi:10.1186/s13104-015-1347-x

8. Hillege HL, Janssen WM, Bak AA, et al. Prevend study group. Microalbuminuria is common, also in a nondiabetic, nonhypertensive population, and an independent indicator of cardiovascular risk factors and cardiovascular morbidity. J Intern Med. 2001;249:519-526. doi: 10.1046/j.13652796.2001.00833.X.

9. Wang Y, Yuan A, Chen Y. Correlation between microalbuminuria and cardiovascular events. Int J Clin Exp Med. 2013;6(10):973978. 
10. Glosing P. Microalbuminuria: a marker of systemic disease. $\mathrm{Br} \mathrm{J}$ Hosp Med. 1995;54:285- 290.

11. Jong PE, Hillege HL, Joan PS, Zeeuw D. Screening for MAU in the general population: A tool to detect subjects at increased risk for progressive renal failure in an early phase.Nephrol Dial Transpl 2003; 18:10-13.

12. American Diabetes Association. Standards of medical care in diabetes-2016. Diabetes Care. 2016; 39 (suppl 1):S1-106.

13. Gupta DK, Verma LK, Khosla PK, Dash SC. The prevalence of MAU in diabetes: a study from north India. Diabetes Res Clin Pr 1991; 2: $125-8$.

14. Vijay V, Snehalatha C, Ramachandran A, Viswanathan M. Prevalence of proteinuria in non-insulin dependent diabetes. J Assoc Physician I 1994; 42:792-4.

15. Ronald Klein, Barbara EK, Scot E Moss. Prevalence of MAU in older -onset diabetes. Diabetes Care 1993; 16(10): 1325-30.

16. Al-Sheikh A. Prevalence of microalbuminuria in type 2 diabetes mellitus at a diabetic clinic in Abualaziz university hospital. Pak J Med Sci. 2000;23(2):223-6. 